Article

\title{
Robust Nocturnal and Early Morning Summer Rainfall Peaks over Continental East Asia in a Global Multiscale Modeling Framework
}

\author{
Yi Zhang ${ }^{1, * \mathbb{C}}$, Haoming Chen ${ }^{1}$ and Dan Wang ${ }^{2}$ \\ 1 State Key Laboratory of Severe Weather (LaSW), Chinese Academy of Meteorological Sciences, \\ China Meteorological Administration, Beijing 100081, China; chenhm@cma.cn \\ 2 Numerical Weather Prediction Center, National Meteorological Center, China Meteorological \\ Administration, Beijing 100081, China; wangd@cma.cn \\ * Correspondence: yizhang@cma.cn
}

Received: 21 January 2019; Accepted: 24 January 2019; Published: 29 January 2019 updates

\begin{abstract}
The diurnal cycle of convection and precipitation is an important atmospheric feature. It also poses a great challenge to global numerical atmospheric modeling. Over continental East Asia, most global models cannot well capture the nocturnal and early morning peaks of summer rainfall. This problem may lead to dry biases and limit the modeling skills. This study investigates this problem using a global multiscale modeling framework (Super-Parameterized CAM5; SPCAM5). The nocturnal and early morning peaks, which are almost absent in CAM5 and a coarser-resolution SPCAM5, can be successfully captured by SPCAM5 with a moderate increase in the horizontal resolution. On the lee side of the Tibetan Plateau, SPCAM5 generates robust eastward propagating rainfall signals, which correspond to the moving convective systems, as revealed by the heating and drying profiles. Over the eastern plain of China, the early morning peaks become more evident, corresponding to a stratiform-type heating structure in the midlevel. A sensitivity experiment with altered grid-scale forcing also suggests the important preconditioning role of the vertical moisture advection in regulating the early morning peaks. These results highlight the added value of representing multiscale processes to the successful simulation of the diurnal cycle over continental East Asia.
\end{abstract}

Keywords: global weather and climate models; convection and precipitation; diurnal cycle; numerical modeling of the atmosphere

\section{Introduction}

The diurnal cycle of convection and precipitation reflects fundamental mechanisms of atmospheric dynamics and physics, and is of great importance to weather and climate. The diurnal variability of rainfall has become a performance metric that poses a great challenge to numerical weather prediction and climate modeling. It is well-known that state-of-the-art global models generally cannot simulate the diurnal features well [1-3], and the reasons that are responsible for the model biases are complex [4-6]. The failure in the simulation of the diurnal cycle of rainfall may result in a systematic dry bias $[7,8]$, leading to an unreliable performance of weather prediction, climate simulation, and future climate projection.

Global models that can resolve multiscale atmospheric dynamics have offered new opportunities. These models generally perform better than conventional models in simulating the diurnal features [9,10]. For example, Dirmeyer et al. [11] provided an analysis of simulations of several representative global models. In their study, increasing the horizontal resolution of a conventional 
general circulation model (GCM) with parameterized physics has little impact on the simulated diurnal cycle. In contrast, the introduction of the super-parameterization (also known as the Multiscale Modeling Framework, or MMF; [12,13]) into a low-resolution GCM results in a significant improvement in the diurnal cycle. Moreover, a global nonhydrostatic model, when configured as a global cloud-resolving model, is found to well simulate the diurnal cycle, and generates features that the conventional GCM at a similar resolution cannot.

Over continental East Asia, a variety of observed diurnal features of summer rainfall has been well documented [14]. However, for most of the general circulation models, a satisfactory simulation of these diurnal features remains an elusive target. In this regard, Zhang and Chen [15] (ZC16 hereafter) compared the Community Atmosphere Model, version 5 (CAM5; [16]) and Super-Parameterized CAM5 (SPCAM5; $[17,18]$ ) simulations of summer precipitation features. At a relatively low horizontal resolution $\left(1.9^{\circ} \times 2.5^{\circ}\right.$, referred to as $2^{\circ}$ hereafter, $\sim 200 \mathrm{~km}$ in the equator), CAM5 simulates the diurnal peaks mostly around noon. SPCAM5, which replaces the CAM5 model physics with an embedded two-dimensional (2D) cloud-resolving model configured at a four-km horizontal resolution, can better simulate a continuous transition stage from shallow to deep convection over regimes dominated by surface heating-induced convection, helping to delay the peak time in the afternoon, and also improve the frequency-intensity structure. Nevertheless, their simulations do not indicate clear nocturnal and early-morning rainfall peaks. This is not an isolated problem for a particular model, but it is also found in many state-of-the-art global climate models [19].

In nature, the nocturnal and early morning rainfall peaks over continental East Asia are usually associated with organized convection and stratiform cloud precipitation [20-22]. They are somewhat similar to those on the lee side of Rocky Mountains over central Great Plains of U.S. [23,24]. Previous studies focusing on the diurnal cycle of rainfall over central U.S. have identified robust eastward propagating rainfall signals in the super-parameterized models $[25,26]$, and suggested that these features are sensitive to specific model configurations [10,25]. Nevertheless, the rainfall modeling problem over continental East Asia is unique due to the distinctive topographic feature and summer monsoon system. The nocturnal and early morning rainfall peaks can occur due to multiple reasons $[14,27,28]$, and pose a great challenge to global weather and climate modeling.

In this study, we show that when the SPCAM5 is configured with a higher external resolution $\left(0.9^{\circ} \times 1.25^{\circ}\right.$, referred to as $1^{\circ}$ hereafter, $\sim 100 \mathrm{~km}$ in the equator), while keeping its internal resolution of the embedded 2D model unchanged, it is able to generate the nocturnal and early-morning rainfall peaks, and exhibits improved simulations of diurnal cycles as compared to CAM5 (which is configured at the same resolution). We further focus on the modeling differences, and explore the possible reasons that may explain the different model behaviors. It would be valuable if we can understand the sensitivity of this problem in a global model, which could help improve the model performance over continental East Asia.

The remainder of this paper is organized as follows. Section 2 describes the model, numerical experiments, data, and methods. Section 3 presents a detailed analysis of the results of numerical modeling. A summary is given in Section 4 .

\section{Model, Numerical Experiments, Data, and Methods}

\subsection{Model and Experiments}

SPCAM5 is a latest version of the SPCAM family (see [29] for a brief introduction). It has two dynamical systems: a large-scale hydrostatic core for the model dynamics, and a two-dimensional cloud-scale anelastic nonhydrostatic core for the model physics, giving it an ability to explicitly simulate multiscale atmospheric dynamics. The sub-grid cloud model of SPCAM5 is configured at a four-km resolution along the east-west direction. Such a resolution is sufficient for resolving the mesoscale dynamics [30,31], while it marginally resolves the shallow convection. 
We adopt the standard Atmospheric Model Intercomparison Project (AMIP) experimental protocol with the prescribed sea surface temperature of each year (2008-2012). Since running SPCAM5 in a $1^{\circ}$ resolution is quite expensive, and our focus is limited to the summer months, an efficient integration approach is used to quantify the modeling difference. For each year between 2008-2012, we initialized the model using the ERA-interim reanalysis data [32] at 00:00 UTC on 31 May. The initialization method is to use the atmospheric state (zonal and meridional winds, temperature, moisture, and surface pressure) in the reanalysis data to replace the state in the initial data (see details in [33]). The model is then continuously integrated over the entire June-July-August (JJA) months. In this manner, we may construct a five-year JJA climate, while avoiding a five-year continuous integration. Previous studies [33-35] have suggested that utilizing the ensemble of discontinuous runs is an efficient approach for comparing the modeling differences, especially for the fast moist processes in the model climate. Note that all of the results shown in this paper come from the $1^{\circ}$-resolution simulations. The $2^{\circ}$ modeling results (also mentioned in certain parts of this paper) are referred to ZC16.

\subsection{Data and Methods}

To measure the observed rainfall features, a high-resolution $\left(0.1^{\circ} \times 0.1^{\circ}\right)$ hourly gauge-satellite merged precipitation dataset [36] (referred to as OBSCMO hereafter) is used. The data have been binned to a $1^{\circ} \times 1^{\circ}$ resolution to match the resolution of the model. To quantify the sub-grid scale diabatic heating and drying, data of an hourly apparent heat source $\left(Q_{1}\right)$ and apparent moisture sink $\left(Q_{2}\right)$ are generated from the grid-scale model states using a residual method [37]:

$$
\begin{aligned}
& \frac{Q_{1}}{c_{p}}=\frac{\partial T}{\partial t}+V \cdot \nabla T-\omega\left(\frac{R T}{c_{p} p}-\frac{\partial T}{\partial p}\right), \\
& \frac{Q_{2}}{c_{p}}=-L\left(\frac{\partial q}{\partial t}+V \cdot \nabla q+\omega \frac{\partial q}{\partial p}\right) / c_{p},
\end{aligned}
$$

where $c_{p}$ is the specific heat constant of dry air, $T$ is the temperature, $q$ denotes the specific humidity, $\omega$ denotes the vertical speed in a pressure-based coordinate, $p$ denotes the pressure, $R$ is the air constant of dry air, $\frac{\partial}{\partial t}$ denotes the time derivation, $V . \nabla$ denotes the horizontal advection, $\omega \frac{\partial}{\partial p}$ denotes the vertical advection, and $L$ is the latent heat of evaporation/condensation. The analysis is performed at constant pressure levels. The unit of $Q_{1} / Q_{2}$ is scaled to $\mathrm{K} \cdot$ day $^{-1}$. Positive values of $Q_{1}$ and $Q_{2}$ denote heating and drying, respectively. The normalized hourly precipitation rate in this paper is given by:

$$
N(h)=\frac{P(h)-\bar{P}}{\bar{P}}
$$

where $N(h)$ is the normalized value, and $P(h)$ is the hourly precipitation rate, and $\bar{P}$ denotes the daily mean value.

\section{Results}

\subsection{Differences in the Simulated Diurnal Cycles}

Figure 1 depicts the diurnal peak time of rainfall over continental East Asia for the summer months (JJA). In OBSCMO, two contrasting rainfall peaks can be observed. Over southeastern China (the right side of the black line), the occurrence of the rainfall maxima is mainly in the late afternoon. Similar to ZC16, SPCAM5 delays the peak time a few hours as compared to CAM5 (Figure 1). On the left side of the black line, SPCAM5 exhibits improved nocturnal and early morning peaks. CAM5 in its $1^{\circ}$ configuration cannot reproduce the nocturnal and early morning peaks (similar to the $2^{\circ}$ case; c.f., ZC16). The diurnal cycle in CAM5 is mainly dominated by the surface solar heating-induced convection, which leads to frequent noontime precipitation maxima. This behavior is in accordance with its deep convection scheme [38], which relates convection with the Convective Available Potential 
Energy (CAPE). Previous studies have proposed alternative procedures to mitigate the adverse impact of such a formulation: for example, by using different triggering functions [39] or by modifying the closure [40]. Moreover, the deep convection scheme of CAM5 does not support the organization memory (e.g., [41,42]), which may limit its ability of simulating the convective system life cycle. Increasing the model resolution does not alleviate such a "missing-physics" problem.

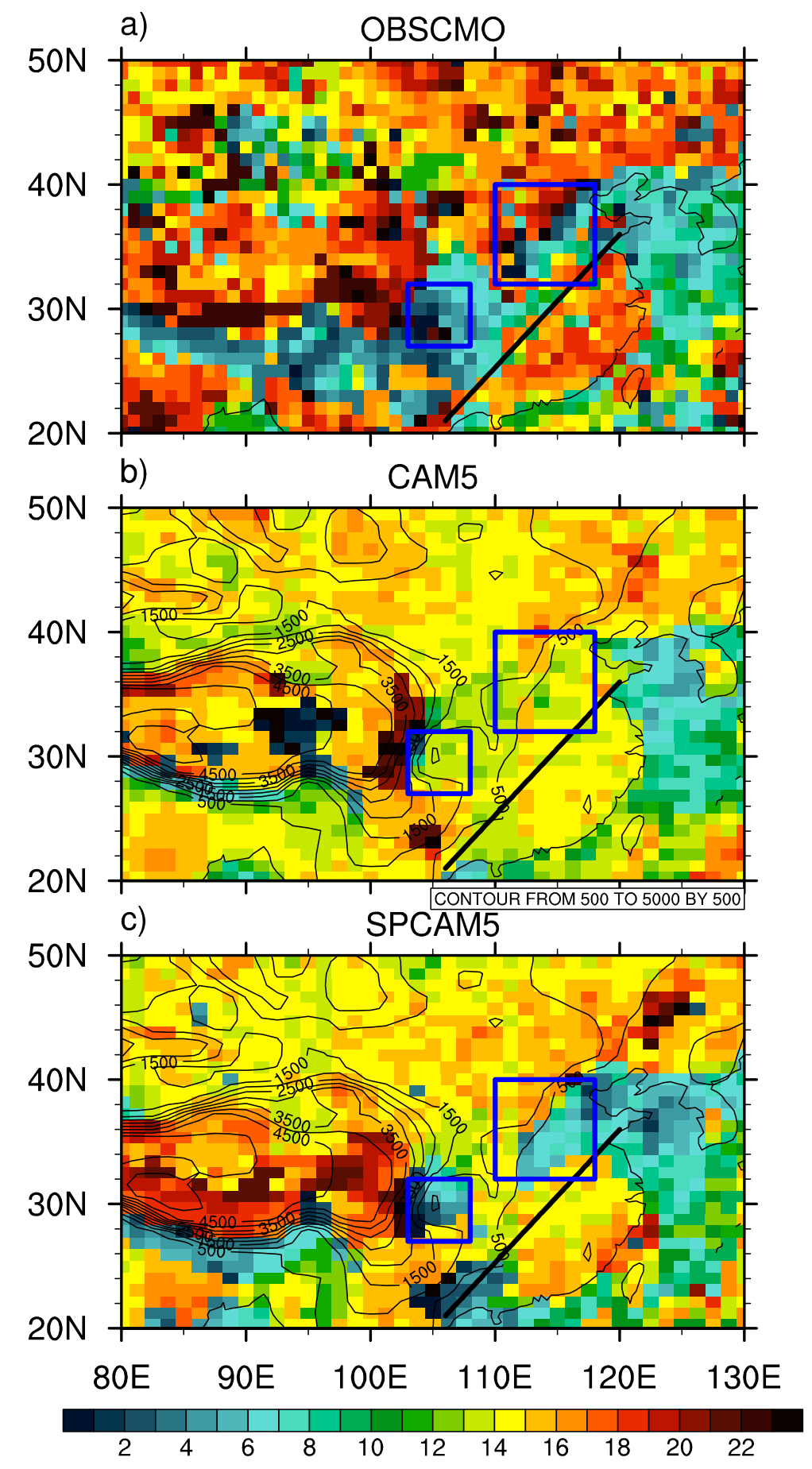

Figure 1. The peak time (local solar time) of rainfall over continental East Asia in, (a) a high-resolution $\left(0.1^{\circ} 0.1^{\circ}\right)$ hourly gauge-satellite merged precipitation dataset (OBSCMO), (b) Community Atmosphere Model, version 5 (CAM5), and (c) Super-Parameterized CAM5 (SPCAM5); the topography of the model is contoured with thin black lines. The two blue boxes show the regions that are analyzed in Figure 2. 
Figure 2 shows the normalized hourly rainfall rates averaged within two representative regions. The first regime (Figure 2a) is on the lee side of the Tibetan Plateau $\left(27-32^{\circ} \mathrm{N}, 103-108^{\circ} \mathrm{E}\right)$, where a single nighttime peak around 04:00 local solar time (LST) is found in the observation. CAM5 simulates a single peak around 14:00 LST. SPCAM5 is able to simulate the dominant nighttime peak around 04:00 LST. SPCAM5 also gives an artificial sub-peak around 15:00 LST as CAM5, but the amplitude is much smaller.

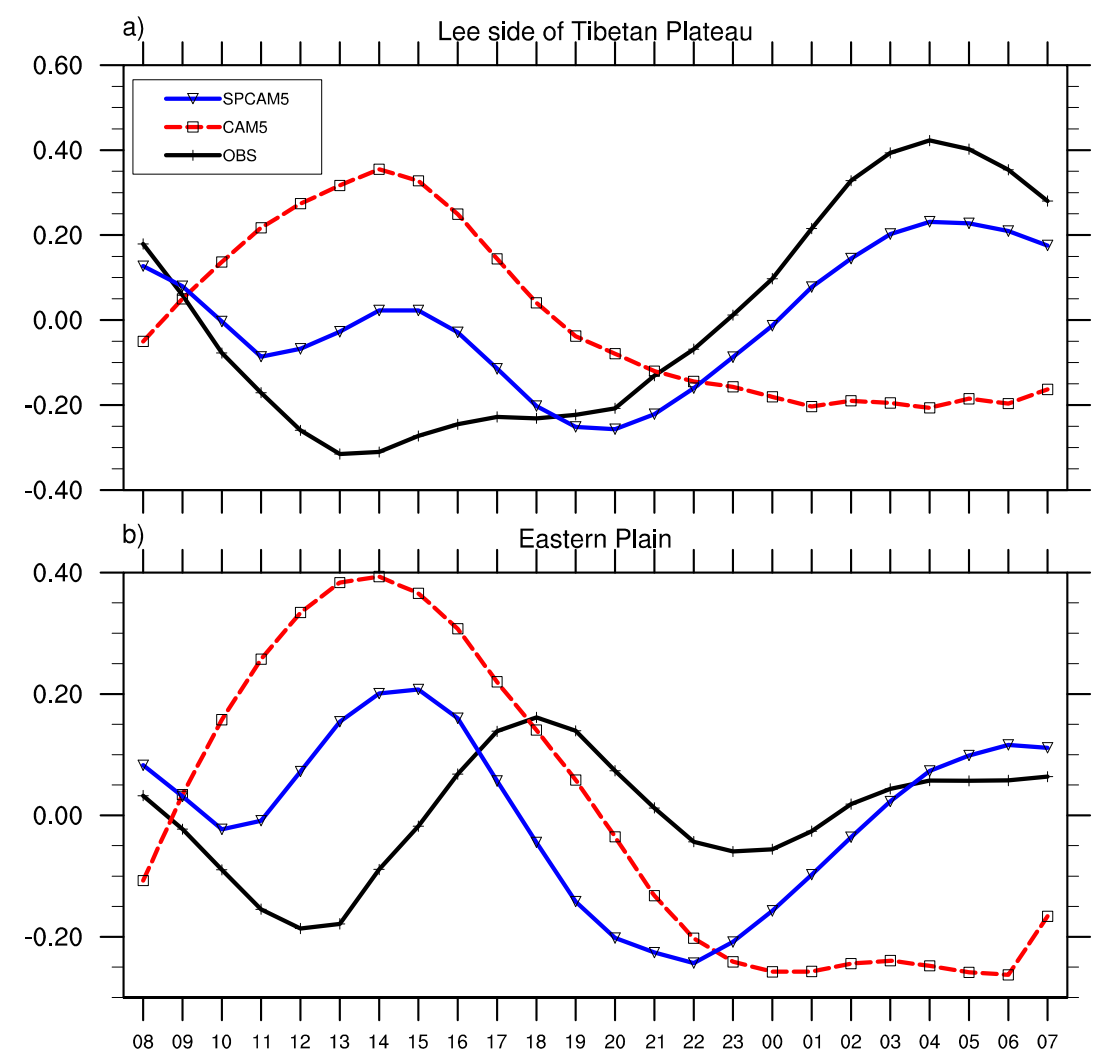

Figure 2. The diurnal cycles of normalized rainfall rates averaged within two regions, (a) on the lee side of the Tibetan Plateau $\left(27-32^{\circ} \mathrm{N}, 103-108^{\circ} \mathrm{E}\right)$, and (b) the eastern plain of China $\left(32-40^{\circ} \mathrm{N}, 110-118^{\circ} \mathrm{E}\right)$; the horizontal axis denotes local solar time.

The second regime (Figure $2 \mathrm{~b})$ is the eastern plain $\left(32-40^{\circ} \mathrm{N}, 110-118^{\circ} \mathrm{E}\right)$, where two peaks are observed: one around 18:00 LST and one during 04:00-07:00 LST, i.e., the coexistence of late afternoon and early morning rainfall peaks. CAM5 only simulates a single peak with a large amplitude around 14:00 LST, while SPCAM5 successfully captures two peaks. The peak in the afternoon is a response to the surface solar heating, which is similar to the case over southeastern China, and is earlier than the observed late-afternoon peak (SPCAM5 slightly delays the peak time). The distinctive early-morning peak is in good agreement with OBSCMO, and will be further studied.

To better illustrate the differences in the diurnal cycle, Hovmöller diagrams (time-longitude contours) of the normalized rainfall rates averaged within $27-32^{\circ} \mathrm{N}$ are shown (Figure 3). Over 100-110 ${ }^{\circ}$ E, OBSCMO shows a clear eastward delayed rainfall signal during 18:00-06:00 LST. The maximum amplitude occurs during the midnight ( 00:00 LST) at $\sim 105^{\circ}$ E. CAM5 does not well simulate the eastward delayed rainfall signals: the rainfall maxima are mainly located to the west of $\sim 103^{\circ} \mathrm{E}$, which is the region that has the largest topographic gradient on the eastern periphery of the Tibetan Plateau (see Figure 1). In SPCAM5, the rainfall maxima extend eastward over time, closer to that in the observation. The maxima in SPCAM5 are located at $\sim 100^{\circ} \mathrm{E}$ in the afternoon ( 16:00 LST, Figure 3c), implying that the model generates more artificial rainfall amounts when forced by the steep topography. By examining the hourly snapshots, we confirmed that most of these propagating rainfall 
signals are continuous in time. In ZC16, a similar Hovmöller diagram was examined for this region (Figure 10 of that paper). The strength of the eastward delayed rainfall signal is much weaker than that shown here. SPCAM5 in its $2^{\circ}$ configuration does not well reproduce the nocturnal and early-morning rainfall peaks over continental East Asia (c.f., ZC16). Based on these results, we may conclude that for SPCAM5, increasing the horizontal resolution is helpful to the simulation of the diurnal cycle.

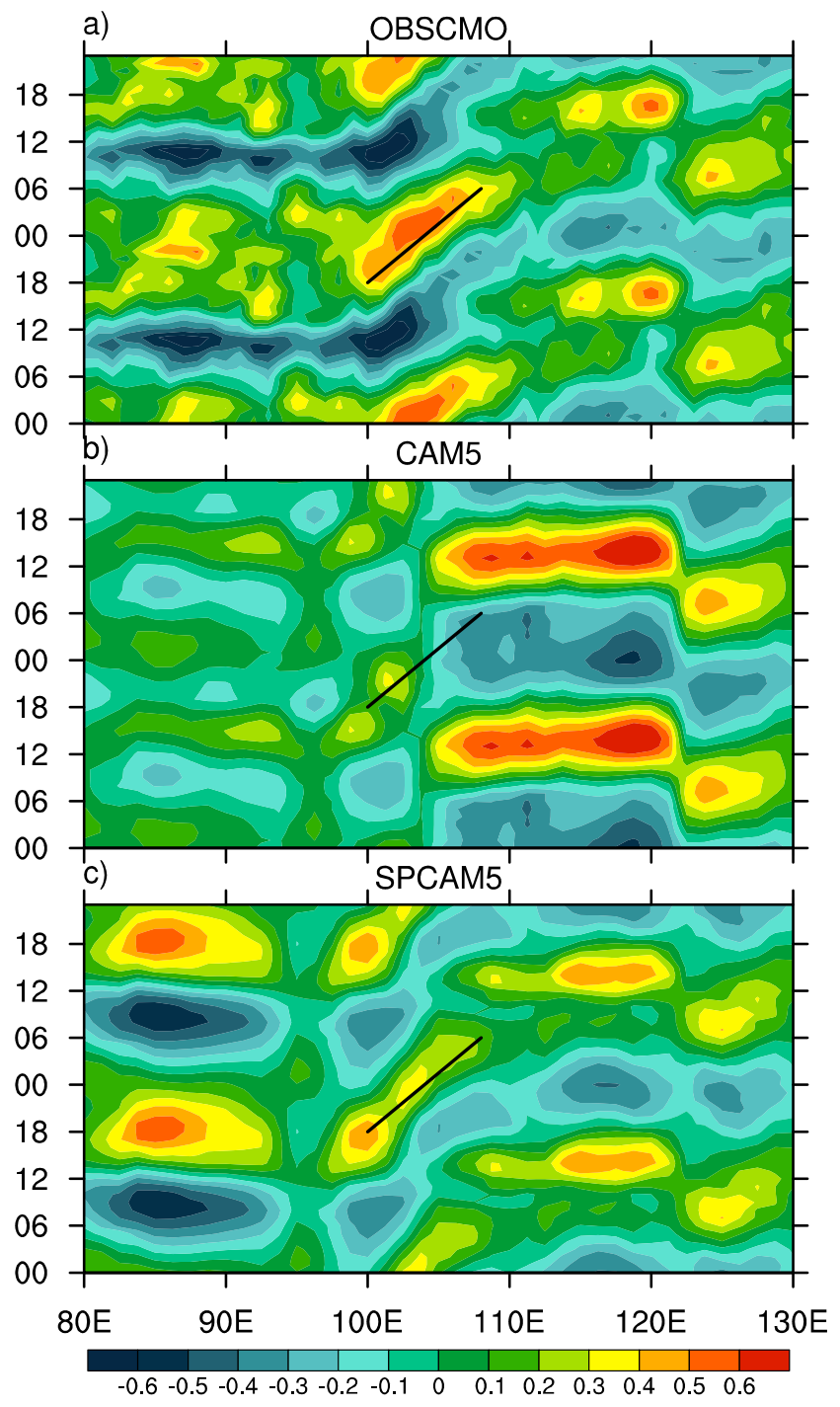

Figure 3. Hovmöller diagrams of the normalized rainfall rates averaged within $27-32^{\circ} \mathrm{N}$ in, (a) OBSCMO, (b) CAM5, and (c) SPCAM5; the horizontal axis denotes the longitude, and the vertical axis denotes the local solar time.

\subsection{Reasons Responsible for the Modeling Differences}

\subsubsection{The Lee Side of the Tibetan Plateau}

The aforementioned analysis has revealed different diurnal features of two models. Since CAM5 and SPCAM5 mainly differ in their sub-grid model physics, the primary reason may be explained from the diurnal progression of $Q_{1}$ and $Q_{2}$ profiles. Figure 4 presents several hour-pressure transects on the lee side of the Tibetan Plateau, averaged within $27-30^{\circ} \mathrm{N}$ at three locations. At $103^{\circ} \mathrm{E}$, both models produce strong surface heating in the afternoon. In SPCAM5, the surface drying during 13:00-16:00 LST is stronger. Moreover, SPCAM5 exhibits stronger nighttime heating and drying than CAM5. Above the heating regime, an upper cooling level is slightly more evident in SPCAM5. This probably 
indicates the stronger upper-level destabilization in SPCAM5: the cloud top longwave cooling in the nighttime tends to create an unstable stratification, which provides a favorable condition for the nighttime convection [43].

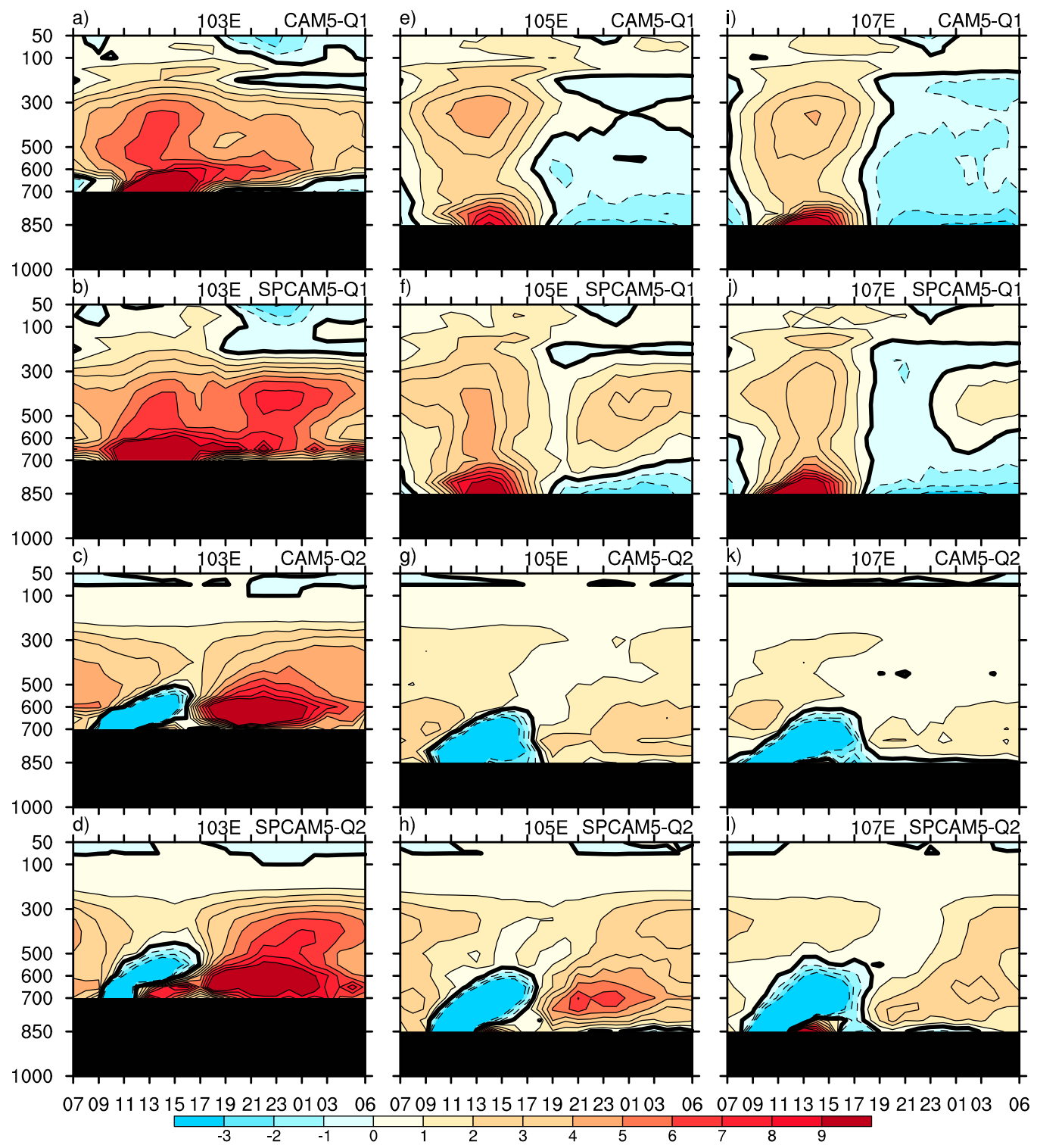

Figure 4. The hour-pressure transects of apparent heat source $\left(Q_{1}\right)$ and apparent moisture $\operatorname{sink}\left(Q_{2}\right)$ averaged within $27-30^{\circ} \mathrm{N}$ at $103^{\circ} \mathrm{E}$ for (a) $Q_{1}$ in CAM5, (b) $Q_{1}$ in SPCAM5, (c) $Q_{2}$ in CAM5, (d) $Q_{2}$ in SPCAM5, (e-h) same as (a-d), but at $105^{\circ} \mathrm{E} ;(\mathbf{i}-\mathbf{l})$ same as $(\mathbf{a}-\mathbf{d})$, but at $107^{\circ} \mathrm{E}$, unit: $\mathrm{K} \cdot \mathrm{day}^{-1}$.

Moving to $105^{\circ} \mathrm{E}$, it is found that CAM5 generates a dominant nighttime cooling trend in the whole troposphere, while SPCAM5 supports heating. Below the heating regime, a surface cooling level is found. The $Q_{2}$ profiles in SPCAM5 show stronger drying in the nighttime. Moving to $107^{\circ} \mathrm{E}, \mathrm{CAM} 5$ simulates stronger nighttime cooling than that in the upstream. SPCAM5 still generates nighttime heating, which is weaker in strength and later in time as compared to its upstream counterpart. In SPCAM5, the $Q_{2}$ profiles show stronger drying from midnight to early morning. Combining these results, it is suggested that the simulated nocturnal and early morning rainfall peaks on the lee side of the Tibetan Plateau are not local phenomena. SPCAM5 supports eastward propagating convection, corresponding to the eastward propagating rainfall signal. The downstream upper-level heating and low-level cooling in SPCAM5 may also imply the existence of stratiform-type precipitation, which is 
usually associated with organized convection [44]. Partly due to the absence of these features, CAM5 produces lower climatological mean rainfall rates over this region than SPCAM5 (Figure S1).

\subsubsection{The Eastern Plain}

For the eastern plain, the observed early morning peak is mostly contributed by precipitation with a relatively long duration [45], suggesting the existence of systematic stratiform cloud precipitation. Figure 5 depicts an hour-pressure transect of $Q_{1}$ and $Q_{2}$ profiles averaged within $32-36^{\circ} \mathrm{N}$, $113-118^{\circ}$ E. This region is mainly dominated by the early-morning rainfall peaks (Figure 1). During 03:00-07:00 LST, SPCAM5 shows stronger midlevel heating than CAM5 between $700 \mathrm{hPa}$ and $300 \mathrm{hPa}$. The upper-level heating and low-level cooling reflect the typical stratiform precipitation systems [46,47]. In SPCAM5, the drying in the early morning is also stronger. For CAM5, although it also produces a stratiform-type heating structure in the early morning (but with weaker magnitude), the normalized rainfall rates are much smaller. A possible reason is that surface heating-induced convection is too active in CAM5, consuming a large portion of the moisture content transported from the boundary layer. This problem is also found in earlier versions of CAM [48].
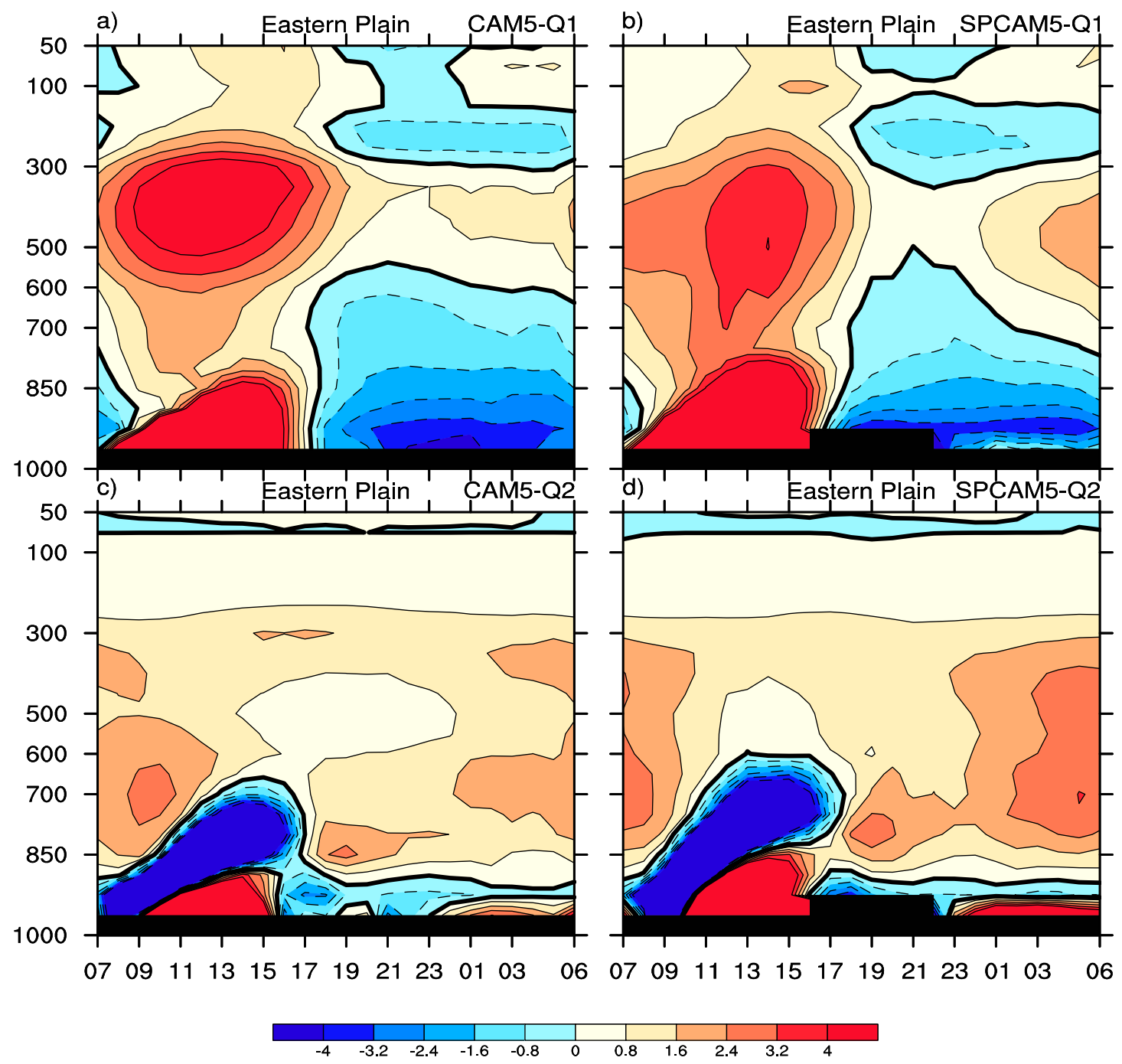

Figure 5. The hour-pressure transects (eastern plain) of apparent heat source $\left(Q_{1}\right)$ and apparent moisture sink $\left(Q_{2}\right)$ averaged within $32-36^{\circ} \mathrm{N}, 113-118^{\circ} \mathrm{E}$, (a) $Q_{1}$ in CAM5, (b) $Q_{1}$ in SPCAM5, (c) $Q_{2}$ in CAM5, (d) $Q_{2}$ in SPCAM5, unit: $\mathrm{K} \cdot$ day $^{-1}$. 
Figure 6 depicts the large-scale environment over this region. Around 01:00-05:00 LST, both models produce favorable large-scale vertical lifting $(\omega)$ and moistening of the vertical advection $\left(-\omega \frac{\partial q}{\partial p}\right)$. The large-scale vertical lifting is partly related to the low-level jet and associated low-level convergence [27,49], which transport abundant moisture. The peak time of the large-scale forcing (before 05:00 LST) is earlier than the peak time of rainfall and sub-grid heating (05:00-07:00 LST), suggesting a preconditioning role of the large-scale forcing. Considering that only SPCAM5 simulates the rainfall maxima in the early morning, these results demonstrate that the favorable large-scale forcing is not sufficient to guarantee a correct simulation of these rainfall peaks. The model physics needs to adequately respond to the grid-scale forcing. Nevertheless, in the following section, we will demonstrate that such favorable large-scale conditions are indeed important in regulating the rainfall signals in this region.
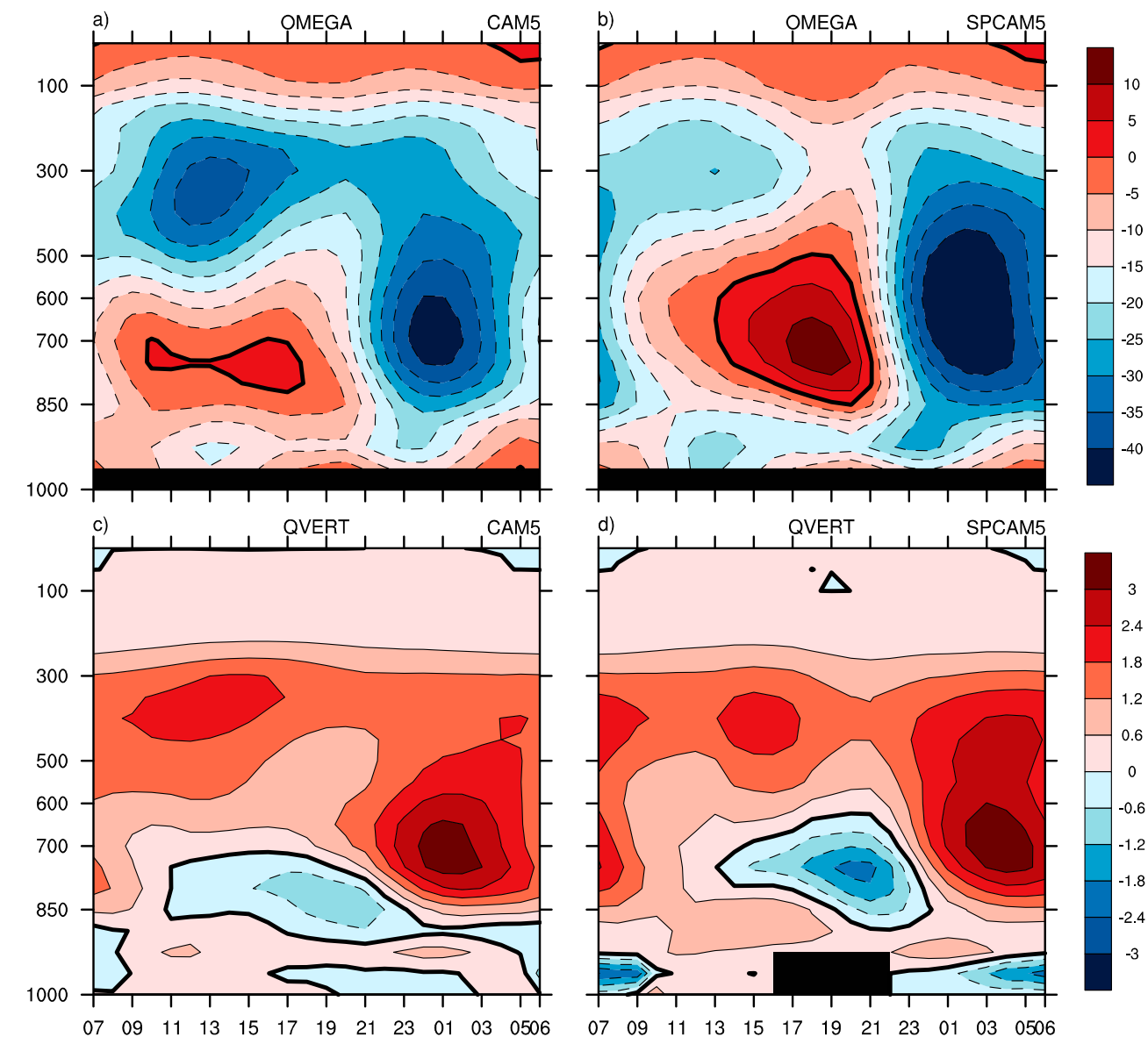

Figure 6. The hour-pressure transects (eastern plain) of the pressure vertical speed (hPa-day ${ }^{-1}$ ) in (a) CAM5 and (b) SPCAM5; the vertical moisture advection tendency (scaled to K·day ${ }^{-1}$ ) in (c) CAM5 and (d) SPCAM5.

\subsection{Impact of the Grid-Scale Forcing}

In previous sections, we have suggested that the occurrence of nocturnal and early morning rainfall peaks is sensitive to the model physics. However, this does not imply that the large-scale circulation is unimportant in terms of regulating these signals. The favorable large-scale forcing serves as an ambient environment, and should also be properly simulated by the model. To illustrate this point, we have performed a numerical experiment (referred to as SPCAM5-topo2d) by coarsening the topographic data in SPCAM5 with data interpolated from the $2^{\circ}$ model (the model resolution remains 
unchanged). The large-scale circulation on the lee side of mountains (note that the eastern plain is also located on the lee side of a secondary terrain) will be altered due to the coarsened topographic data.

The diurnal peak time of rainfall in SPCAM5-topo2d is shown in Figure 7. The early morning peaks over the eastern plain largely disappear. Interestingly, the eastward delayed rainfall signals on the lee side of the Tibetan Plateau are still simulated by the model. This may also imply that the precipitation mechanisms over these two regions are different, as we have analyzed. Next, we mainly focus on the eastern plain because of the more evident change.

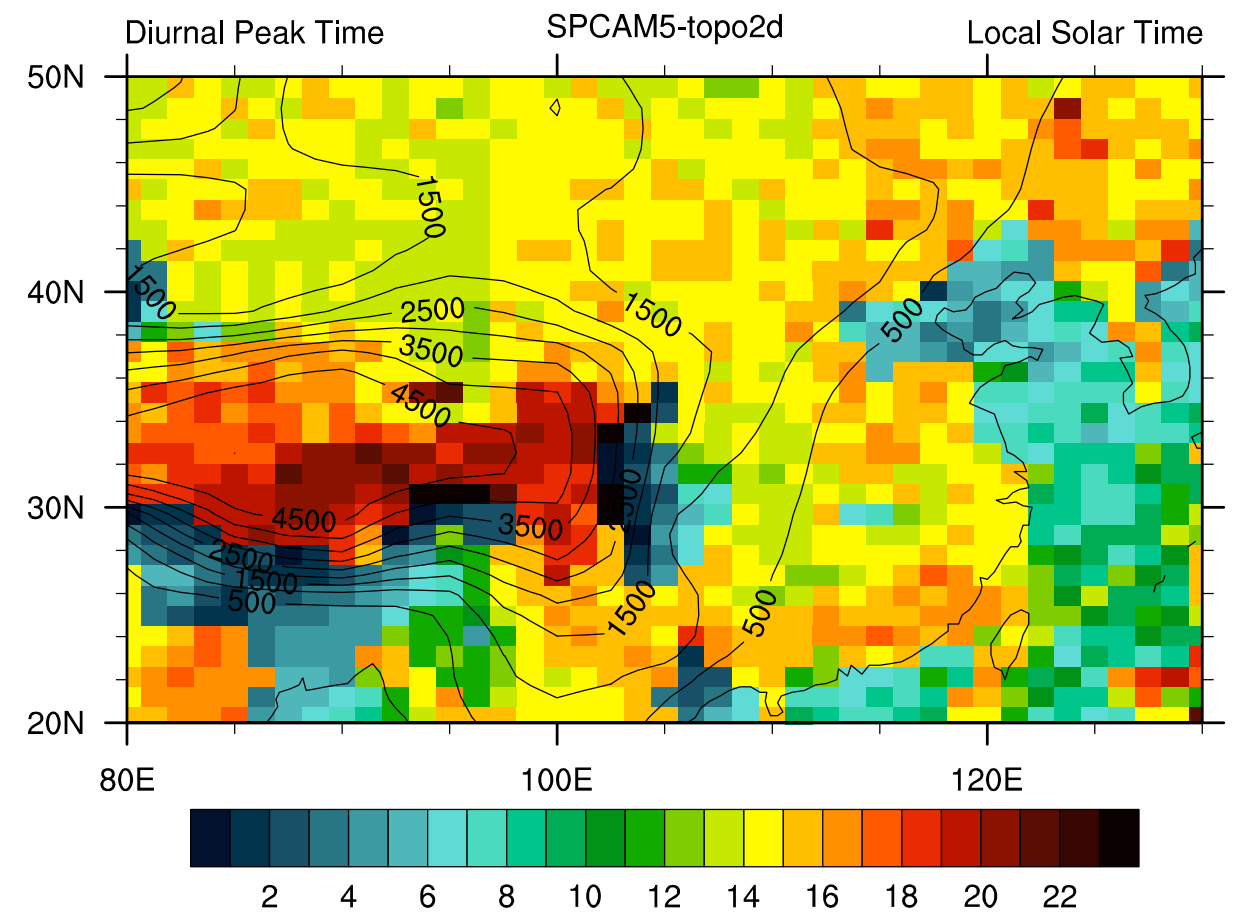

Figure 7. The peak time (local solar time) of rainfall over continental East Asia in SPCAM5-topo2d; the topography is contoured with thin black lines.

Figure 8 compares the grid-scale model states and tendencies, and sub-grid heating over the eastern plain. During 01:00-05:00 LST, the strong rising motion and vertical moisture advection in SPCAM5 are largely weakened by SPCAM5-topo2d, suggesting that the modified topographic forcing has altered the large-scale environment. Correspondingly, the midlevel diabatic heating strength also decreases from SPCAM5 to SPCAM5-topo2d, showing a response of sub-grid processes to the altered large-scale forcing. As a result, the early morning rainfall maxima in SPCAM5-topo2d largely disappear due to the unfavorable large-scale environment that hinders strong moisture transport. These results suggest that the preconditioning role of the large-scale forcing is indeed an important factor to the simulation of these early-morning rainfall peaks. If the contribution from the large-scale forcing is weakened, the rainfall process will be suppressed. 

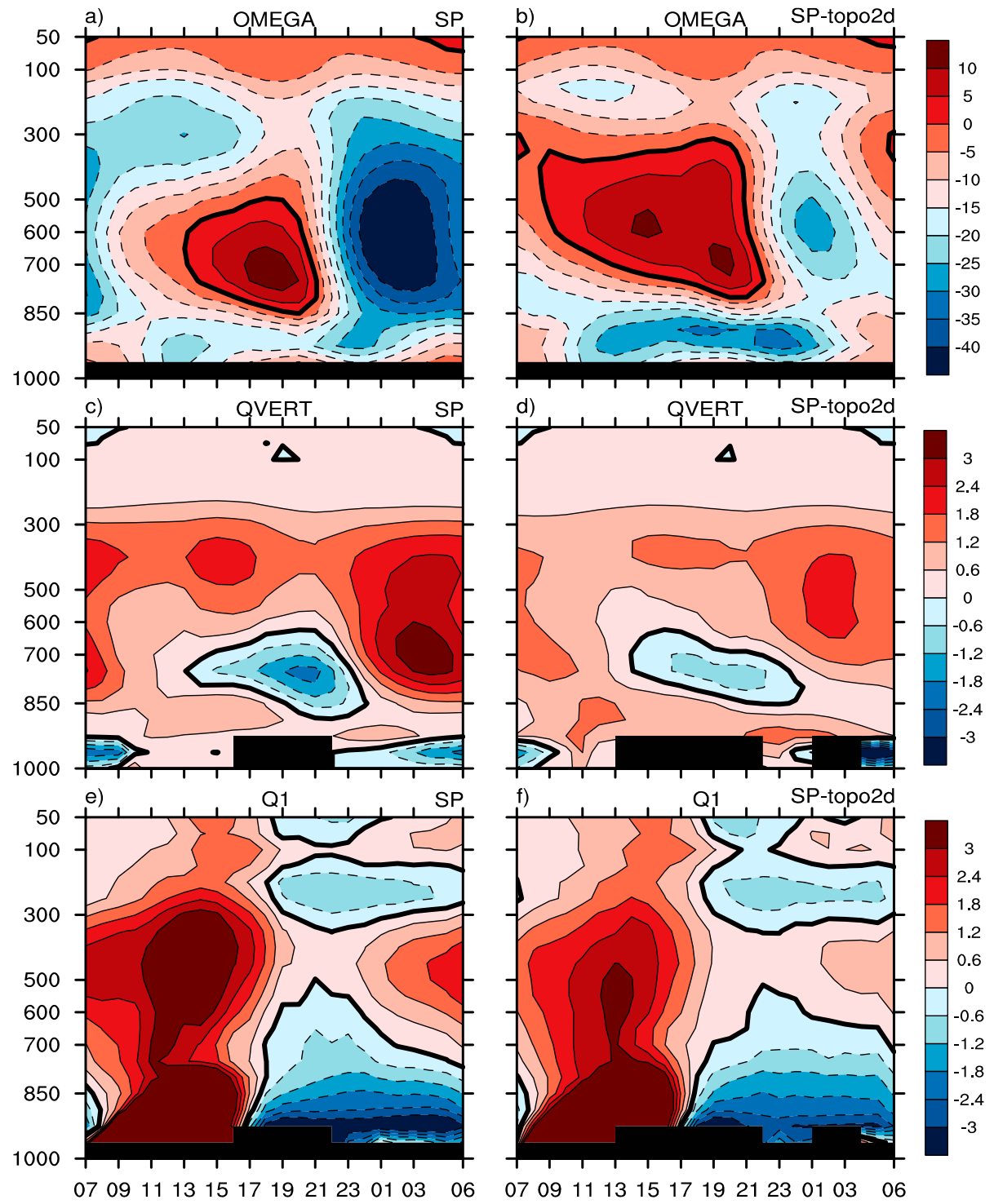

Figure 8. The hour-pressure transects (eastern plain) averaged within $32-36^{\circ} \mathrm{N}, 113-118^{\circ} \mathrm{E}$, $(\mathbf{a}, \mathbf{b})$ the pressure vertical speed $\left(\mathrm{hPa} \cdot \mathrm{day}^{-1}\right)$ in SPCAM5 and SPCAM5-topo2d, (c,d) the vertical

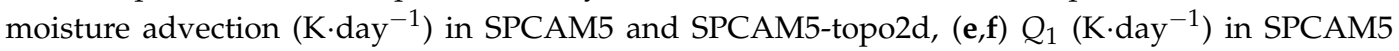
and SPCAM5-topo2d.

\section{Conclusions}

In this paper, we focus on the simulations of nocturnal and early morning rainfall peaks in a global multiscale modeling framework. It is encouraging that SPCAM5 is able to simulate distinctive regional features of the diurnal cycles. Compared to an earlier study that used lower-resolution models (ZC16), more significant differences between CAM5 and SPCAM5 are found, and possible reasons have been explored. The major conclusions are summarized as follows.

With a moderate increase of the horizontal resolution from $\sim 2^{\circ}$ to $\sim 1^{\circ}$, SPCAM 5 can well simulate the nocturnal and early morning peaks of summer rainfall over continental East Asia. The heating and drying profiles show that SPCAM5 supports the nocturnal eastward propagating convection on the lee side of the Tibetan Plateau, leading to the improved eastward propagating rainfall episodes and associated rainfall maxima. It is also found that SPCAM5 better simulates the early morning peaks over the eastern plain of China than CAM5, corresponding to the stratiform-type rainfall maxima. For SPCAM5, a sensitivity experiment using coarsened topographic data shows a deterioration of early 
morning rainfall maxima over the eastern plain. This is caused by the weakened large-scale vertical rising motion and associated moisture transport. The resultant unfavorable large-scale forcing leads to a reduction of the early morning rainfall amounts, and decreases the midlevel heating magnitude, further confirming the important preconditioning role of the large-scale forcing in regulating these stratiform rainfall peaks.

Altogether, these results highlight the importance of representing multiscale processes to the successful simulation of the diurnal cycle over continental East Asia. Partly motivated by the successful simulations of SPCAM, we are currently developing a global nonhydrostatic modeling system based on the quasi-uniform grid for supporting multiscale atmospheric modeling. Some progress in the model dynamical framework has been achieved (c.f., [50-52]), and we hope that we may report interesting modeling results in the future.

Supplementary Materials: The following are available online at http:/ /www.mdpi.com/2073-4433/10/2/53/s1, Figure S1: The difference of five-year mean precipitation rates (unit: $\mathrm{mm} \cdot \mathrm{day}^{-1}$ ) in June-July-August (JJA) months between CAM5 and SPCAM5 (CAM5 minus SPCAM5) over continental East Asia.

Author Contributions: Conceptualization, Y.Z.; Formal analysis, Y.Z. and H.C.; Investigation, Y.Z., H.C. and D.W.; Methodology, Y.Z.; Validation, Y.Z., H.C. and D.W.; Visualization, Y.Z. and D.W.; Writing-original draft, Y.Z.; Writing-review and editing, Y.Z., H.C. and D.W.

Funding: This study is jointly supported by the National Key R\&D Program of China (2016YFA0602101), the National Natural Science Foundation of China $(41875135,41505066)$ and the National Key R\&D Program of China (2017YFC1502200).

Acknowledgments: Data used for this study are stored at a local disk array and are available upon request. The CAM5 and SPCAM5 models are provided by the National Center for Atmospheric Research. The helpful comments of two anonymous reviewers are appreciated.

Conflicts of Interest: The authors declare no conflict of interest.

\section{References}

1. Dai, A.; Trenberth, K.E. The Diurnal Cycle and Its Depiction in the Community Climate System Model. J. Clim. 2004, 17, 930-951. [CrossRef]

2. Jiang, J.H.; Su, H.; Zhai, C.; Shen, T.J.; Wu, T.; Zhang, J.; Cole, J.N.S.; von Salzen, K.; Donner, L.J.; Seman, C.; et al. Evaluating the Diurnal Cycle of Upper-Tropospheric Ice Clouds in Climate Models Using SMILES Observations. J. Atmos. Sci. 2014, 72, 1022-1044. [CrossRef]

3. Covey, C.; Gleckler, P.J.; Doutriaux, C.; Williams, D.N.; Dai, A.; Fasullo, J.; Trenberth, K.; Berg, A. Metrics for the Diurnal Cycle of Precipitation: Toward Routine Benchmarks for Climate Models. J. Clim. 2016, 29, 4461-4471. [CrossRef]

4. Bechtold, P.; Chaboureau, J.P.; Beljaars, A.; Betts, A.K.; Köhler, M.; Miller, M.; Redelsperger, J.L. The simulation of the diurnal cycle of convective precipitation over land in a global model. Q. J. R. Meteor. Soc. 2004, 130, 3119-3137. [CrossRef]

5. Guichard, F.; Petch, J.C.; Redelsperger, J.L.; Bechtold, P.; Chaboureau, J.P.; Cheinet, S.; Grabowski, W.; Grenier, H.; Jones, C.G.; Köhler, M.; et al. Modelling the diurnal cycle of deep precipitating convection over land with cloud-resolving models and single-column models. Q. J. R. Meteor. Soc. 2004, 130, 3139-3172. [CrossRef]

6. Rio, C.; Hourdin, F.; Grandpeix, J.Y.; Lafore, J.P. Shifting the diurnal cycle of parameterized deep convection over land. Geophys. Res. Lett. 2009, 36. [CrossRef]

7. Klein, S.A.; Jiang, X.; Boyle, J.; Malyshev, S.; Xie, S. Diagnosis of the summertime warm and dry bias over the U.S. Southern Great Plains in the GFDL climate model using a weather forecasting approach. Geophys. Res. Lett. 2006, 33. [CrossRef]

8. Lee, M.-I.; Schubert, S.D.; Suarez, M.J.; Held, I.M.; Kumar, A.; Bell, T.L.; Schemm, J.-K.E.; Lau, N.-C.; Ploshay, J.J.; Kim, H.-K.; et al. Sensitivity to Horizontal Resolution in the AGCM Simulations of Warm Season Diurnal Cycle of Precipitation over the United States and Northern Mexico. J. Clim. 2007, 20, 1862-1881. [CrossRef] 
9. Sato, T.; Miura, H.; Satoh, M.; Takayabu, Y.N.; Wang, Y. Diurnal Cycle of Precipitation in the Tropics Simulated in a Global Cloud-Resolving Model. J. Clim. 2009, 22, 4809-4826. [CrossRef]

10. Pritchard, M.S.; Somerville, R.C.J. Assessing the Diurnal Cycle of Precipitation in a Multi-Scale Climate Model. J. Adv. Model. Earth Syst. 2009, 1. [CrossRef]

11. Dirmeyer, P.; Cash, B.; Kinter, J., III; Jung, T.; Marx, L.; Satoh, M.; Stan, C.; Tomita, H.; Towers, P.; Wedi, N. Simulating the diurnal cycle of rainfall in global climate models: Resolution versus parameterization. Clim. Dyn. 2012, 39, 399-418. [CrossRef]

12. Grabowski, W.W.; Smolarkiewicz, P.K. Proceedings of the 1999 International Symposium on Physical Design, Monterey, CA, USA, 12-14 April 1999.

13. Khairoutdinov, M.F.; Randall, D.A. A cloud resolving model as a cloud parameterization in the NCAR Community Climate System Model: Preliminary results. Geophys. Res. Lett. 2001, 28, 3617-3620. [CrossRef]

14. Yu, R.; Li, J.; Chen, H.; Yuan, W. Progress in studies of the precipitation diurnal variation over contiguous China. J. Meteorol. Res. 2014, 28, 877-902. [CrossRef]

15. Zhang, Y.; Chen, H. Comparing CAM5 and Superparameterized CAM5 Simulations of Summer Precipitation Characteristics over Continental East Asia: Mean State, Frequency-Intensity Relationship, Diurnal Cycle, and Influencing Factors. J. Clim. 2016, 1067-1089. [CrossRef]

16. Description of the NCAR Community Atmosphere Model (CAM 5.0). Available online: http:/ / www.cesm. ucar.edu/models/cesm1.0/cam/docs/description/cam5_desc.pdf (accessed on 21 January 2019).

17. Wang, M.; Ghan, S.; Easter, R.; Ovchinnikov, M.; Liu, X.; Kassianov, E.; Qian, Y.; Gustafson Jr, W.I.; Larson, V.E.; Schanen, D.P.; et al. The multi-scale aerosol-climate model PNNL-MMF: Model description and evaluation. Geosci. Model. Dev. 2011, 4, 137-168. [CrossRef]

18. Wang, M.; Larson, V.E.; Ghan, S.; Ovchinnikov, M.; Schanen, D.P.; Xiao, H.; Liu, X.; Rasch, P.; Guo, Z. A multiscale modeling framework model (superparameterized CAM5) with a higher-order turbulence closure: Model description and low-cloud simulations. J. Adv. Model. Earth Syst. 2015, 7, 484-509. [CrossRef]

19. Yuan, W. Diurnal cycles of precipitation over subtropical China in IPCC AR5 AMIP simulations. Adv. Atmos. Sci. 2013, 30, 1679-1694. [CrossRef]

20. Wang, C.-C.; Chen, G.T.-J.; Carbone, R.E. A Climatology of Warm-Season Cloud Patterns over East Asia Based on GMS Infrared Brightness Temperature Observations. Mon. Weather Rev. 2004, 132, 1606-1629. [CrossRef]

21. Yu, R.; Yuan, W.; Li, J.; Fu, Y. Diurnal phase of late-night against late-afternoon of stratiform and convective precipitation in summer southern contiguous China. Clim. Dyn. 2010, 35, 567-576. [CrossRef]

22. Chen, G.; Yoshida, R.; Sha, W.; Iwasaki, T.; Qin, H. Convective Instability Associated with the Eastward-Propagating Rainfall Episodes over Eastern China during the Warm Season. J. Clim. 2013, 27, 2331-2339. [CrossRef]

23. Carbone, R.E.; Tuttle, J.D.; Ahijevych, D.A.; Trier, S.B. Inferences of Predictability Associated with Warm Season Precipitation Episodes. J. Atmos. Sci. 2002, 59, 2033-2056. [CrossRef]

24. Tuttle, J.D.; Davis, C.A. Corridors of Warm Season Precipitation in the Central United States. Mon. Weather Rev. 2006, 134, 2297-2317. [CrossRef]

25. Pritchard, M.S.; Moncrieff, M.W.; Somerville, R.C.J. Orogenic Propagating Precipitation Systems over the United States in a Global Climate Model with Embedded Explicit Convection. J. Atmos. Sci. 2011, 68, 1821-1840. [CrossRef]

26. Kooperman, G.J.; Pritchard, M.S.; Somerville, R.C.J. Robustness and sensitivities of central U.S. summer convection in the super-parameterized CAM: Multi-model intercomparison with a new regional EOF index. Geophys. Res. Lett. 2013, 40, 3287-3291. [CrossRef]

27. Chen, H.; Yu, R.; Li, J.; Yuan, W.; Zhou, T. Why Nocturnal Long-Duration Rainfall Presents an Eastward-Delayed Diurnal Phase of Rainfall down the Yangtze River Valley. J. Clim. 2010, 23, 905-917. [CrossRef]

28. Chen, G.; Sha, W.; Iwasaki, T.; Wen, Z. Diurnal Cycle of a Heavy Rainfall Corridor over East Asia. Mon. Weather Rev. 2017, 145, 3365-3389. [CrossRef]

29. Randall, D.; Branson, M.; Wang, M.; Ghan, S.; Craig, C.; Gettelman, A.; Edwards, J. A Community Atmosphere Model With Superparameterized Clouds. Eos. Trans. Am. Geophys. Union 2013, 94, 221-222. [CrossRef] 
30. Weisman, M.L.; Skamarock, W.C.; Klemp, J.B. The Resolution Dependence of Explicitly Modeled Convective Systems. Mon. Weather Rev. 1997, 125, 527-548. [CrossRef]

31. Yang, Q.; Houze, R.A.; Leung, L.R.; Feng, Z. Environments of Long-Lived Mesoscale Convective Systems Over the Central United States in Convection Permitting Climate Simulations. J. Geophys. Res. Atmos. 2017, 122. [CrossRef]

32. Dee, D.P.; Uppala, S.M.; Simmons, A.J.; Berrisford, P.; Poli, P.; Kobayashi, S.; Andrae, U.; Balmaseda, M.A.; Balsamo, G.; Bauer, P. The ERA-Interim reanalysis: Configuration and performance of the data assimilation system. Q. J. R. Meteor. Soc. 2011, 137, 553-597. [CrossRef]

33. Zhang, Y.; Chen, H.; Yu, R. Simulations of Stratus Clouds over Eastern China in CAM5: Sources of Errors. J. Clim. 2015, 28, 36-55. [CrossRef]

34. Zhang, Y.; Li, J. Impact of moisture divergence on systematic errors in precipitation around the Tibetan Plateau in a general circulation model. Clim. Dyn. 2016, 47, 2923-2934. [CrossRef]

35. Zhang, Y.; Chen, H.; Yu, R. Simulations of Stratus Clouds over Eastern China in CAM5: Sensitivity to Horizontal Resolution. J. Clim. 2014, 27, 7033-7052. [CrossRef]

36. Shen, Y.; Zhao, P.; Pan, Y.; Yu, J. A high spatiotemporal gauge-satellite merged precipitation analysis over China. J. Geophys. Res. Atmos. 2014, 119, 3063-3075. [CrossRef]

37. Yanai, M.; Esbensen, S.; Chu, J.-H. Determination of Bulk Properties of Tropical Cloud Clusters from Large-Scale Heat and Moisture Budgets. J. Atmos. Sci. 1973, 30, 611-627. [CrossRef]

38. Zhang, G.; McFarlane, N. Sensitivity of climate simulations to the parameterization of cumulus convection in the Canadian Climate Centre general circulation model. Atmos. Ocean. 1995, 33, 407-446. [CrossRef]

39. Xie, S.; Zhang, M. Impact of the convection triggering function on single-column model simulations. J. Geophys. Res. Atmos. 2000, 105, 14983-14996. [CrossRef]

40. Zhang, G.J. Convective quasi-equilibrium in midlatitude continental environment and its effect on convective parameterization. J. Geophys. Res. Atmos. 2002, 107. [CrossRef]

41. Donner, L.J. A Cumulus Parameterization Including Mass Fluxes, Vertical Momentum Dynamics, and Mesoscale Effects. J. Atmos. Sci. 1993, 50, 889-906. [CrossRef]

42. Mapes, B.; Neale, R. Parameterizing Convective Organization to Escape the Entrainment Dilemma. J. Adv. Model. Earth Syst. 2011, 3. [CrossRef]

43. Lee, M.-I.; Choi, I.; Tao, W.-K.; Schubert, S.; Kang, I.-S. Mechanisms of diurnal precipitation over the US Great Plains: A cloud resolving model perspective. Clim. Dyn. 2010, 34, 419-437. [CrossRef]

44. Houze, R.A. Cloud Dynamics. Int. Geophys. 2014, 104, 432.

45. Yu, R.; Xu, Y.; Zhou, T.; Li, J. Relation between rainfall duration and diurnal variation in the warm season precipitation over central eastern China. Geophys. Res. Lett. 2007, 34, L13703. [CrossRef]

46. Lin, J.; Mapes, B.; Zhang, M.; Newman, M. Stratiform Precipitation, Vertical Heating Profiles, and the Madden-Julian Oscillation. J. Atmos. Sci. 2004, 61, 296-309. [CrossRef]

47. Del Genio, A.D.; Wu, J.; Chen, Y. Characteristics of Mesoscale Organization in WRF Simulations of Convection during TWP-ICE. J. Clim. 2012, 25, 5666-5688. [CrossRef]

48. Song, X.; Yu, R. Underestimated tropical stratiform precipitation in the National Center for Atmospheric Research (NCAR) Community Climate Model (CCM3). Geophys. Res. Lett. 2004, 31, L24101. [CrossRef]

49. Liu, H.; He, M.; Wang, B.; Zhang, Q. Advances in low-level jet research and future prospects. J. Meteorol. Res. 2014, 28, 57-75. [CrossRef]

50. Zhang, Y.; Yu, R.; Li, J. Implementation of a conservative two-step shape-preserving advection scheme on a spherical icosahedral hexagonal geodesic grid. Adv. Atmos. Sci. 2017, 34, 411-427. [CrossRef]

51. Zhang, Y. Extending High-Order Flux Operators on Spherical Icosahedral Grids and Their Applications in the Framework of a Shallow Water Model. J. Adv. Model. Earth Syst. 2018, 10, 145-164. [CrossRef]

52. Zhang, Y.; Li, J.; Yu, R.; Zhang, S.; Liu, Z.; Huang, J.; Zhou, Y. A Layer-based Nonhydrostatic Dynamical Framework on an Unstructured Mesh for Global and Regional Atmospheric Modeling: Model Description, Baseline Evaluation and Sensitivity Exploration. J. Adv. Model. Earth Syst. 2019, under revision.

(C) 2019 by the authors. Licensee MDPI, Basel, Switzerland. This article is an open access article distributed under the terms and conditions of the Creative Commons Attribution (CC BY) license (http:/ / creativecommons.org/licenses/by/4.0/). 